\title{
Modernity, the Individual, and the Foundations of Cultural-Historical Activity Theory
}

\author{
Andy Blunden \\ Independent Social Research Network, Australia
}

\begin{abstract}
It is argued that the problem of individual agency in relation to social institutions can be resolved within Cultural-Historical Activity Theory (CHAT) by the use of the "subject" as a unit of analysis. Such an approach implies a reaffirmation of the fundamental tenets of CHAT but also a critique of the concepts of society and culture, which are appropriated by psychology. A successful critique of objectivist conceptions of society and culture requires an appropriate framing of the concept of subject.
\end{abstract}

Two recent articles published in Mind, Culture, and Activity (Billett, 2006; Stetsenko, 2005) touched on the issue of the need for psychology in general, or Cultural-Historical Activity Theory (CHAT) in particular, to better reflect the capacity of individuals to exercise genuine agency alongside larger social forces. Stetsenko, for example, aimed to reveal:

(a) individual and collective processes as being interrelated and co-evolving levels of activity, and (b) the practical relevance of human subjectivity alongside the human relevance of material practices. (p. 70)

These writers observed, and rightly, that although the internalization of norms and discourses by individuals is well described by psychology in general, and CHAT in particular, the way in which individuals modify and create social rules, institutions, and ideology, and thereby exercise a degree of self-determination, is less well understood. Failing a more critical appropriation of the concepts of cultural and social formations involved in the constitution of consciousness, psychology risks erring in the direction of objectivism, casting individuals as creatures of the culture and institutions within which they live, minimizing the way in which people create their own lives, inclusive of the culture and social formations which condition them.

The accusation of objectivism cannot be leveled at some other trends in psychology such as cognitivism, for whom the individual is taken for granted as a free agent. But CHAT has long since demonstrated the inadequacy of such individualism in science.

Dorothy Holland (see Holland, Lachicotte, Skinner, \& Cain, 2001) has expressed the contradiction at work here as that of culturalism versus constructivism; that is, on one hand, psychologies that see the individual as a passive carrier of dominant cultural values and ideology, and on the other hand, psychologies that see the individual as capable of freely negotiating

Correspondence should be sent to Andy Blunden, 165 Barkly St., Brunswick, Victoria, Australia 3056. Email: ablunden@mira.net 
subject positions and theoretical paradigms from among the myriad of narratives made available in a modern society, constructing for themselves their own biography.

This contradiction is also found in sociological and historical theories between liberal individualism (including mainstream economic theory and liberal political theory, for example) and various forms of structuralism and poststructuralism, and in ethical theory in the dispute between liberalism and communitarianism, and so on.

As suggested by Dorothy Holland and others, what is needed is a "third position" that avoids the one-sided extremes expressed on each side of these contradictions. But what this means for the foundations of CHAT is not immediately clear. Most literature of early decades when the foundations of the theory were laid down, reads as strongly communitarian and objectivist. But as a psychology, rather than a sociology or political theory, CHAT self-evidently theorizes the individual psyche, and not social formations, ideologies, and institutions. The charge of "objectivism" can hardly be sustained in relation to CHAT. Probably the only psychology against which a charge of objectivism could be sustained would be behaviorism, which rejects the existence of consciousness altogether.

The pioneers of CHAT participated in a strongly communitarian ethos, in the young USSR and in the Progressive Movement in the United States. The kind of progressive communitarianism of these writers is sharply at odds with the spirit of postmodernity, which emphasizes two contradictory elements: on one hand, extreme individualism, to the point of pathological narcissism, and on the other hand, a fatalistic anomie and alienation, in which the individual perceives the institutions of society as inhuman, alien, and all-powerful. The identity of the individual with vast and powerful social movements can no longer be taken for granted. In fact, it no longer exists. And this is the problem.

The observation that CHAT still lives within the ethos of progressive communitarianism neither casts doubt over the validity of its theory nor suggests that its ethos is outmoded. But it does suggest a reason why CHAT is challenged by the way postmodern capitalism is unfolding. The fault is not however so much with how psychology conceives of the individual as how the social sciences conceive of culture and society and whether psychology appropriates concepts these sciences uncritically.

It has long been a truism of orthodox Marxism that it is a mistake to theorize society and history in terms of the laws of individual behavior (e.g., "Life of the individual organism is subject to quite different laws from those of the social life"; Kautsky, 1902, p. 340). History, economy, and society, it is said, obey social and historical laws, not the laws of the individual psyche. This never prevented the founders of CHAT, however, theorizing the individual psyche in terms of society. But what is left out of this dichotomy is culture. Fashioned out of what is given by nature, culture is subject to objective constraints. Among such constraints are the "rules" that are manifested in the behavior of institutions such as the market, the state, technological innovation, and so on, as well as the objective constraints imposed on the human body, which is as much a cultural product as our domestic animals and our clothes, fashioned from the material provided by nature to fit in with other artifacts in a definite form of life.

The dichotomy implied in the ban on the theorization of society (economics, class struggle, discourse, etc.) in psychological terms forgets that a social law must also of necessity equally be a law of individual action. And Marx himself demonstrated this in founding his critique of political economy on the commodity, that is to say, on the relation of exchange between two subjects. Provided social theory is not based on an individualist, idealist, or culturalist theory of 
psychology, but on the psychology of cultural-historical activity, there is no barrier in principle to bridging the gap between psychology and social theory by renovating the foundations not of psychology, but of social theory. Instead of revising the foundations of CHAT to upgrade the notion of individual agency in social formations, the problem then becomes extending the foundations of CHAT so as to better theorize culture and social formations, not solely as context and resource, but also as manifestations of the psyche.

What plagues all attempts to resolve this problem is the persistent dichotomy between the individual on one side and society (subsuming both culture and activity) on the other. This dichotomy, so long as it is maintained, blocks all possibility of solution to the problem: "It is particularly important to guard against understanding human activity as a relationship that exists between man and an opposing society” (Leontyev, 1978, §3.2).

One form of the dichotomy is the idea of two "levels" or "domains" of activity. A well-argued form of this dichotomy is that of Habermas (1987) and others: on one hand, activity in the public sphere, in which the dominant actors are institutions and other social formations, governed by laws, rules, and social expectations; on the other hand, individual activity, manifested for example in the ever-shrinking private sphere. Although a dichotomy between private and public domain has merit, it cannot provide a foundation to resolve the problem before us, because it leaves out the cultural landscape which conditions the relations between public and private spheres.

Another form of the dichotomy is that formulated by Heller (1988) and Putnam (1993, 2000), among others, between the "thick ethos" that pervades and regulates the activity within institutions and the "thin ethos" that extends across the entire society, regulating interactions between strangers.

A practical-critical appropriation of social and cultural theory can best be effected by relying on "intermediate concepts," such the system of wage determination, the legal system, corporate structure, mode of regulation, and so on, without supposing that these institutions are somehow determined without mediation by grand ensembles such as the "mode of production." Such an approach is adopted by Regulation Theory (Boyer, 1990), which theorizes capitalism in terms of finite entities whose dynamics can be revealed through Activity Theory, rather than being deduced from a grand synthesis.

Although the temptation to theorize individual agency in terms of interactions between social and individual levels or domains is strong, it is quite mistaken. What is at issue here is what is known as the "unit of analysis," a unit of analysis that encompasses both individual and social.

CHAT is founded on a trichotomy. Several suggestions can be found for such a basic trichotomy. For example, Leontyev (1977) mentions the subject-activity-object relation, and Vygotsky (1987-1999, Vol. 3.) mentions the stimulus-psychological tool-response relation, or "signs" or "sign-stimuli" in lieu of "psychological tools." In the American tradition, Peirce (1931-1958) has object-sign-interpretant. To resolve the problem before us, the basic unit of analysis (or trichotomy) must be the subject. The subject-object relation is unquestionably of fundamental concern and may be the subject of a further article, but it is necessary to begin with the subject itself.

The Hegelian roots of this conception are examined shortly, but in CHAT terminology, the trichotomy is (a) the individual, that is, the single, mortal human psyche; (b) culture, that is, the mass of objects or artifacts that are inherited from the past and only spring into life when they are used by individuals—buildings, languages, crops, laws, libraries, technology, and so 
on; and (c) society, that is, the particular, continuing corporate activities in which individuals use culture in collaborative activities or conflict and are taken up by one individual as another leaves off. Each of these three aspects of human life can be the subject of sciences in their own right. Psychology is concerned with the individual psyche, natural science and the arts with culture, and the social sciences with society. As CHAT has amply demonstrated, the individual psyche can be understood only as an aspect of this larger, fundamental unit of analysis: the subject. The same is true of the study of social institutions like business enterprises, states, markets, social movements, and so on, as much as it is also true of the study of language, art, technology, nature, and so on. This poses the problem of reframing the study of the social and cultural aspects of mind based on the subject as the common unit of analysis.

The following feature of this approach should be noted. The three moments just mentioned can in no way be conceived as distinct "levels" or "spheres" of activity. I am not suggesting (a) a private sphere of personal activity or an internal world of feelings and beliefs, or (b) a sphere of cultural activity, pursing science, literature, and art, alongside (c) a public sphere or domain of institutions, movements, classes, and so forth. On the contrary, every single activity, action, relation, or thought is simultaneously partaking of all three moments. That is what is meant by a unit of analysis. If I say that the tree outside my window is a ficus, no one would take this to mean that "tree" and "ficus" exist side by side with this individual tree. Nor is "subject" a synonym for "individual," as it is in most social theory, but rather a dynamic unity of an individual, culture, and activity.

The individual human psyche is formed as a person grows up and is shaped by culture and society; society evolves through conquest, trade, migration of peoples, and class struggles, shaped by technical innovation, concentration of capital, religion, and so on; the culture created by people in the various historical forms of their association is accumulated and passed on, modified or lost in its own specific ways. Different concepts are required to theorize each of these processes. But in no case do we have anything other than individual human beings using artifacts inherited from the past (or newly created) to collaborate and compete with other human beings in specific social formations (i.e., subjects).

The task at hand is not to introduce a new individual "level" alongside the cultural-historical "level" but rather to abolish all objectivist, structuralist, and reified conceptions of society by renovating them along the lines that they are the activity of individual human beings utilizing artifacts as a means of collaborating with (or fighting) one another.

Modernity is characterized by the carrying through of the commodification of social relations, culture, and activity. This fragmentation of the social fabric has led to the demise of social movements, the loss of legitimacy of states, and the destruction of social cohesion and community. The result is that, on one hand, those institutions that are supported by capital take on an aura of supernatural powers governing social life, but expressing the ideals, aspirations and identity of no one, and on the other hand, a pathological narcissism-anomic individuals guided only by the pursuit of pleasure, celebrity, and the accumulation of goods, living in fear of catastrophe in a world of unknown dangers and alien powers. In this context, "agency" has been transformed into a parody; postmodern writers talk of agency mainly in terms of niche markets and free trade.

Such a condition cannot and should not be imported into psychology, but rather the task is a critique of modernity. Such a critique means that the notion of "subject" must not be understood in the Kantian sense as a transcendental individual, but neither can it be understood simply in the form of "collective subjects," the corporate actors that populate international politics and 
social struggles, or the "subject position" known to poststructuralists. This kind of dichotomy of subjects-individual subjects on one hand and social subjects on the other-is exactly the kind of approach that needs to be transcended. What is left out in each case is the mediating role of material culture.

Leontyev referred to a "doubling" of subjective meanings resulting from the elaboration of the division of labor and in particular the exploitation of wage labor:

[Shared meaning] disintegrates along with the disintegration of the original relationships between individuals and the material conditions and means of production, along with the emergence of the social division of labour and private property. The result is that socially evolved meanings begin to live a kind of double life in the consciousness of individuals. (Leontyev, 1977, p. 197)

On one hand, changes in social practice, in particular the destruction of relations of cooperation, mean that systems of activity do not correspond to the meaning attached to them by individuals, as just explained by Leontyev. But also, shared cultural products-laws, social myths, cities, and so on-may be at odds with the systems of activity they encompass, as well as the conceptions of the individuals living them out.

[The] real duality of the existence of meanings for the subject ... lies in the fact that meanings present themselves to the subject both in their independent existence - as objects of his consciousness-and at the same time as the means and "mechanism" of comprehension. (Leontyev, 1977, p. 195)

Three distinct contradictions are involved here: (a) Social practices may be at odds with the subjective conceptions of the individuals performing them as well as (b) the cultural norms and laws that formerly and supposedly govern them. (c) Meanings sedimented in cultural forms, such as language and laws, may be in contradiction with the meanings implicit in evolving social practices. All three contradictions are powerful levers of social change and will be manifested as contradictions in the psychology of individuals.

\section{WHAT IS MEANT BY "SUBJECT"?}

By subject, I understand a self-conscious system of activity. A subject is therefore the identity of agency (or moral responsibility, the capacity to do something), "cogito" (knowledge or understanding), and self-consciousness (or identity). Agency, cogito, and self-consciousness are however never in absolute identity with one another; the identity of agency, cogito, and self-consciousness is a process, never complete or fully adequate at any given point.

The individual person is a limiting case of a subject, but in general, the individual-as-subject can only be the endpoint of a long-drawn-out, still-unfinished historical process. This trichotomy constitutes the definition of subject and allows the development of subjectivity to be traced through the independent development, reciprocal transformation, intersection, relative unity, and contradictions between its three components. As such this definition bridges the sciences of ethics, sociology, political science, psychology, and so forth. The theoretical understanding of the subject and its development requires an analytical conception that makes it possible to understand just how moral capacity, understanding, and identity develop. Vygotsky and Leontyev are the foremost pioneers in the theorization of the subject from the standpoint 
of psychology, particularly learning; there are some more recent Marxists whose ideas offer suggestions for a new approach of the understanding of social formations as well. But first let us look at the approach of Hegel.

Hegel was surely the first person to theorize the subject from the standpoint of culturalhistorical activity. In his first systematic work, The System of Ethical Life (Hegel, 1979), written before he developed the notion of Geist (Spirit or Mind), Hegel described the development of a subject in terms of the made (as opposed to presupposed) unity of Concept (i.e., language, culture, social institutions, etc.) and Intuition (i.e., practical activity, sensuous experience, etc.), a unity he called Idea (Idee). Successively, Concept is subsumed under Intuition and Intuition is subsumed under the Concept, leading to an increasingly adequate unity. This process can be understood to reflect the development of a modern state, or of an individual person or institution of some kind. This dialectical approach of defining the object of investigation as the identity of two originally separate processes that intersect, is the same dialectic that makes its appearance in Vygotsky's (1987-1999, Vol. 1) famous Thinking and Speech: "Up to a certain point, speech and thinking develop along different lines and independently of one another. At a certain point, the two lines cross: thinking becomes verbal and speech intellectual" (p. 112).

Hegel's explanation of how this development takes place is surprisingly materialistic, given the idealistic form of Hegel's exposition and his self-definition as an "idealist." According to Hegel, the three processes by which individuals appropriate and create culture and history are (a) labor, including the making and use of tools; (b) language and the use of words (the "tools of Reason"); and (c) the raising of children. This triad is mentioned but not fully elaborated. In this early work, there is also developed a trichotomy that reaches its most perfected, and admittedly obtuse, form in the section of the Science of Logic on Subjectivity (Hegel, 1969).

Here Hegel defines the subject as the identity of three moments, each of which mediates the other two: Individual (e.g., meaning a single, finite, mortal individual psyche), Particular (e.g., meaning the continuing activity of individuals in definite, continuing forms of social practice), and Universal (e.g., meaning the eternal and universal products of culture mobilized in activity and mediating the activity of individuals). This notion can be utilized to achieve a radicalization of notions of social subjectivity, not just at the individual level as already achieved by CHAT but also in relation to culture and society.

This notion of Subjectivity is transcended in the Logic in the relation Subject-Object-Idea but is given its clearest expression in the structure of the Encyclopedia of Philosophical Sciences in terms of the following trichotomy.

Hegel theorizes Geist as the unfolding (rather than made) unity of Subjective Spirit, Objective Spirit, and Absolute Spirit. By Subjective Spirit can be understood "habitus" in the meaning given to this term by Bourdieu (1984), that is, the "intuitive" understanding of people acquired in day-to-day life, including life within the great institutions of society. Objective Spirit can be understood as the totality of the institutions, laws, practices, and associations of the wider society, which are reflected in the understanding of those who live within them, but have an objective existence independent of the consciousness of any individual, including family, economic, and political life. Under Absolute Spirit, Hegel includes Art, Religion, and Philosophy, those universal and binding products of society that transcend interpersonal and institutional relations.

It would be a mistake to take Hegel's analytical distinction to refer to three domains of activity. For Hegel, the individuals participating in the various social institutions described as 
Objective Spirit, for example, can do so only insofar as those institutions are appropriated in Subjective Spirit, and in the way they do so they create and give expression to Absolute Spirit. In the words of Leontyev (1977),

Despite all its diversity, all its special features the activity of the human individual is a system that obeys the system of relations of society. Outside these relations human activity does not exist. How it exists is determined by the forms and means of material and spiritual communication that are generated by the development of production and that cannot be realised except in the activity of specific individuals. (p. 182)

Hegel's system made it possible to theorize the reification of subjective, objective, and absolute spirit into separate domains, and indeed that reification made it possible for Hegel to theorize them. But his meaning is that all three moments are identified in Spirit. For example, people objectively participating in a certain discourse or form of activity is something quite different from a subjective understanding of that activity. Those participating in it may or may not have a particular subjective conception of what they are doing. That is the difference between objective and subjective spirit.

Hegel wrote a long time ago, at the dawn of modernity. I do not propose that his system or method be resuscitated today. However, I think the designation of Hegel as the first culturalhistorical activity theorist has some merit, and his writings provide a wealth of forms for the current task. From the various formulations to be found in Hegel's works, I propose to render the conception of the subject as the unity of the Individual, Particular, and Universal as follows.

A subject has three components: (a) The individual, simply understood as a mortal individual human spirit or psyche, with whatever capacity for moral responsibility, whatever knowledge, beliefs, and ideology they hold and with a certain identity or self-consciousness; (b) the ensemble of social relations and activities, including both collaborative and conflictual relations, both production relations and the entire range of activities, whether in the private domain, the economy, the arts, or whatever; and (c) the Universal, material products of culture, inclusive of language, the means of production, technology and science, the land, buildings, and so on. The human body itself or hexis, though mortal with the human individual whose body it is, I subsume under material culture, as it is a cultural product and mediates between the psyche and activity. The problem of nature versus nurture can only be resolved by empirical investigation.

This conception has been abstracted from various formulations to be found in Hegel's work, as a unit of analysis adequate to the task before us. What is important about Hegel's Individual-Particular-Universal trichotomy is that it is a universal relation, more or less the same relation as Peirce's Qualisign-Sinnisign-Logosign. In some instance the "Individual" might be an individual psyche, in another the individual human organism, in another an artifact or social formation. It depends on the object of study, the problem to be solved. It represents the basic structure of a "unit of analysis" or notion.

The individual is a concrete abstraction; the individual human psyche is absolutely confined to one organism separate from all others. And yet the entirety of human history is present in it. Every time I use the English language and choose either an Anglo-Saxon or a Latin word, I continue the Battle of Hastings. No one system of activity exhausts the individual psyche. Billett's (2006) observation that individuals bring all the past experiences into any institution in which they participate is making this same point, but what Billett overlooked is that this same 
fact, which he construed as proving something about individuals, equally demonstrates that systems of activity interpenetrate and are only relatively independent one another (cf. Leontyev's [1978, §5] notion of "personal meaning") and that every artifact belongs to a larger culture and is materially connected to every other artifact. The unique experience that every individual brings into a particular interaction is equally evidence of the heterogeneity and indivisibility of society and culture, and of itself proves nothing about "individual agency."

The particular, on the other hand, is always a relative abstraction. You can't draw a line between one system of activity and another or isolate it from the larger systems of activity of which it is a part. But whereas the individual psyche is trapped within its body, one and the same system of activity is instantiated in different individuals from one moment to another. The particular (e.g., some institution) is not really an existing thing at all, because its existence rests on individuals using culture in a particular way. Discourse theory takes the first (sceptical) step in understanding the conditionality of institutions but overlooks the sedimented activity deposited in material culture, which gives dogmatic force to the existence of institutions as material things. Naïve understanding, conversely, mistakes institutions for material things because it fails to recognize that the artifacts that give it material existence may be subject to a different interpretation. Structuralism forgets that institutions gain their force thanks to the praxis of the individuals involved and cannot be deduced from some totalizing abstraction existing apart from individual actors.

You can no more have an idea in the head of a dead person than find life in a language that no living person can interpret. And yet the universal mediates all human activity. Culturalism overestimates the independence of the Universal in governing social life, because for various reasons the practical activities that gave life to an element of culture may cease and what was previously a powerful ideal may become nothing but a dead lump of matter or an "empty word." Constructivism overestimates the element of free will in the use of culture because it forgets that the universal is not only ideal but also material. Culture imposes itself on those who would disregard it by the hard force of dead matter.

To show that this or that current of theory takes a one-sided standpoint is not to discount its achievements. Rather, this observation facilitates the appropriation of the insights of the various schools of social theory.

Let us turn to the work of the founders of CHAT. In his critique of the Stimulus-Reaction notion of behavior, Vygotsky proposed the inclusion of a mediating link, a "psychological tool," between the stimulus and response as being the crucial building block of consciousness. Leontyev characterized this idea in the following terms: "The crux of Vygotsky's idea is that only the tripartite schema which cannot be further decomposed can be the minimal unit of analysis which preserves the basic properties of the mental functions" (Vygotsky, 1987-1999, Vol. 3, p. 24). The "psychological tool" is also both stimulus and reaction, obedient to the laws of nature, but something which is constructed, that is, a product of cultural activity:

Artificial acts are natural as well. They can, without remainder, to the very end, be decomposed and reduced to natural ones, just like any machine (or technical tool) can, without remainder, be decomposed into a system of natural forces and processes. What is artificial is the combination (construction) and direction, the substitution and utilisation of these natural processes. (pp. 85-86)

Like any artifact, the nervous system so constructed is a social product, which makes its appearance only in and through the collaboration of the individual with others within 
some kind of social practice. "Each higher form of behaviour enters the scene twice in its development-first as a collective form of behaviour, as an inter-psychological function, then as an intra-psychological function, as a certain way of behaving" (p. 95). And,

The operation of using a sign, ... stands at the beginning of the development of each of the higher mental functions, initially has, of necessity, a character of external activity. At first, as a rule, the sign is an external auxiliary stimulus, an external means of autostimulation. This is due to two factors: first, to the origin of this operation from a group form of behaviour that always belongs to the sphere of external activity, and, second, to the primitive laws of the individual sphere of behaviour, which in its development has still not separated from external activity. (Vol. 6., p. 11)

Once the process of internalization is complete, however, the distinction between the artifact, which may begin its life as an objective material thing outside consciousness, albeit a thing endowed with social significance, has become integrated into the psyche itself and cannot be said to be something other than the psyche. The same can be said of the activity of consciousness in relation to other people and an artifact; this activity ceases to be something that the psyche does but rather is the psyche itself. In Leontyev's (1977) words, "Man's activity is the substance of his consciousness" (p. 202) or as Fichte (2000) put it, "The self is pure activity" (p. 4).

Vygotsky's key idea about the construction of consciousness is based on how we learn; learning takes place through the collaboration of the novice with an adult member of the culture using some artifact to allow the novice to complete some operation they need to become a full and able member of the society. That artifact may be a sign or any other kind of useful thing provided by society for the achievement of social ends, or a role model (a symbol, index or icon, Peirce's, 1931-1958, terms). Children learn to coordinate their own activity using the artifact and then gradually internalize the activity so that the use of an objective thing, spoken word, and so on, may no longer be necessary but is taken over by internal functions within their own body.

The essential components of this learning action are the individual child, the artifact, and the "representative" of society. As the learning proceeds, the artifact is transformed into a kind of node within the psyche, that is, a "psychological tool." At this point, the child acts like any adult member of the society (skipping over here the long-drawn-out process of transformation that takes place during the process of internalization or appropriation) so that the distinction between the material and mental aspects of the element of culture is secondary and relative; the artifact is an "ideal" or "universal." The outcome is not the insertion of the ideal into some kind of mental substance but rather the restructuring of the nervous system with the individual coordinating their activity by means of the ideal, which remains an element of material culture. When we talk of activity, then, we are talking of the coordination of the activity of two or more individuals in some kind of social practice by means of socially constructed signs. This includes the coordination by the individual of their own body so as to act in relation to the entire society and its culture, irrespective of the immediate presence of any other person. In the limiting case of such activity, then, the person acts in relation to his or her own body as a cultural product. In play, for example, the child can turn any object into a prop for the purpose of activities that she does not yet have the ability to carry out in reality.

The unit of analysis for a subject as conceived of by Vygotsky is therefore an individual person, an element of culture, and an activity or material practice. In the process of development, these elements, which begin as distinct components of psychic activity, become identified in 
the subject as a single unit of behavior. So Vygotsky's conception of subjectivity is consonant with the idea proposed here as a conception of the subject.

Vygotsky worked in the early Soviet Union; it was taken for granted, apparently, that "growing up" entailed becoming a competent and morally responsible citizen of the Soviet Union. Whatever private criticisms they harbored, in their scientific work the founders of CHAT conceived of culture and society as integral and relatively unproblematic entities, capable of representing the aspirations of every individual. The adult person would be an individual member of the state (or the workers' movement in the case of a capitalist country), in much the way that Aristotle conceived of the subject as a citizen of the polis. But the situation is entirely different in postmodern capitalist society. There is no identification of the person with the state or with society as a whole or even a class; the adults who interact with a child "belong" to a society or culture but do not "represent" it. The endpoint of development is an anomic individual who does not see in any institution a representation of their own identity and aspirations.

Leontyev was blessed with living much longer than his comrade Vygotsky, and his activity theory represents a real development of the ideas generally associated with the name of Vygotsky. Leontyev's activity theory is not in contradiction to Vygotsky's ideas, however, nor does his activity theory supersede Vygotsky ideas. In a strong sense, Leontyev's approach complements that of Vygotsky. As previously mentioned, a subject is defined as a "selfconscious system of activity," and although this idea is consistent with Hegel's conception of the subject, it is Leontyev that has given us modern explication of this idea in the science of psychology.

Once we acknowledge the common structure of external practical activity and internal mental activity, we can understand the exchange of elements that constantly takes place between them. We can understand that certain mental actions may become part of the structure of direct practical material activity, and, conversely, external-motor operations may serve the performance of mental action in the structure of purely cognitive activity (Leontyev, 1977).

Leontyev (1978) showed us how systems of activity develop according to their own dynamics, particularly in the elaboration of the division of labor, and how this process generates ever new "systems of activity" along with the artifacts that come into being as a result of their special meaning in a specific system of activity and correspondingly in concepts or thought-forms.

Concepts are the result of a process of assimilation of "ready-made," historically evolved meanings, and this process takes place in the child's activity during its intercourse with the people around it. In learning to perform certain actions, the child masters the corresponding operations, which are, in fact, in a compressed, idealised form, represented in meaning. (Leontyev, 1977, p. 194)

Leontyev focused on the object-relatedness of the activity of a subject, including motives and more immediate goals, fundamental to the emergence of the subject itself.

Activity is a process of intertraffic between opposite poles, subject and object ... The basic, constituent feature of activity is that it has an object. In fact, the very concept of activity (doing, Tätigkeit) implies the concept of the object of activity. (pp. 181-182)

These ideas bring into focus the social processes of change and development that lie somewhat in the background in Vygotsky's analysis of learning, for which the division of labor figures 
as a given, "represented" to the novice learner through her interaction with an adult member of society. Conversely, in Leontyev's approach, material culture moves somewhat into the background relative to practical activity. For example, when Leontyev (1977) said,

A problem that is always a stumbling block in the analysis of consciousness ... is the problem of the specific nature of the functioning of knowledge, concepts, conceptual models, etc., in the system of social relations, in the social consciousness, on the one hand, and, on the other, in the individual's activity that realises his social relations, in the individual consciousness. (p. 194)

it is altogether unclear exactly what is meant by "social consciousness" as opposed to "individual consciousness." This elides the contradiction between meanings implicit in social practice, on one hand, and meanings embodied in material culture, on the other hand.

To be sure, both Vygotsky and Leontyev are concerned with sign- or artifact-mediated, objected-oriented activity. It is just a difference in emphasis. Taken together, these two bodies of theory constitute the foundations of CHAT and are fully consonant with the Hegelian ideas just sketched. But instead of the concept of an extramundane Geist animating human history, following Marx, Vygotsky, and Leontyev, their comrades and successors have given us a "pragmatic" interpretation that does away with the need for any extramundane and totalizing spirit.

It was previously mentioned that the unit of analysis required for the solution of the problem of subjectivity is not the interaction between two domains or spheres of activity. But it should be mentioned at this point that such a concept of interacting systems of activity is a perfectly valid idea, provided the interaction is conceived with an appropriate moment of mediation. Leontyev's ideas are particularly rich in facilitating the theorization of such interactions.

To return to the point. The problem of understanding how individuals appropriate and practically critique the social formations of which they are a part depends on the use of an appropriate "unit of analysis," or in Hegelian terms, "notion." It was argued that the appropriate unit of analysis is the subject, understood as a self-conscious system of activity, necessarily embodying a relative unity of agency, cogito, and self-consciousness, with individual, particular, and universal moments. Such a unit of analysis is not the property of psychology alone but equally facilitates understanding how cultural objects and social formations change through the activity of individuals.

Stetsenko (2005) argued that Marx's dichotomy between material production and the "superstructure" ought to figure in the unit of analysis relevant to solution of this problem. In what was previously argued here, these two domains of activity are subsumed under "activity." Leontyev also made this distinction between production and communication very prominent in his approach, but for Leontyev also, both are subsumed under activity. Obviously in implementation of any analysis of individual agency a finer grain of analysis is needed beyond subsuming the entirety of social institutions under "activity" and the entirety of culture, whether in the arts, commerce, or production, under "culture." I argue nonetheless that the fundamental unit of analysis is the subject, that is, psyche-activity-culture.

But even beyond this, the dichotomy of "material production" on one side and "intersubjective exchanges" on the other is misconceived. Marx's basic insight that the production and reproduction of life is the starting point for a scientific conception of society and history remains unchallenged but since the advent of Taylorism, Fordism, and Toyotism, and so on, over the more than a century since Marx's death, have abolished a number of formerly stable 
distinctions. It is no longer possible to draw a line between productive labor and the supervision of labor, between production and commerce, and so on. Leontyev (1977) mentioned the same observation: "In the present age, when the integration and interpenetration of [mental and practical] forms of human activity is taking place before our eyes, when the historic opposition between them is being steadily and increasingly erased" (p. 184). Further, after exploring the relations between production, distribution, and exchange in the Grundrisse (Marx \& Engels, 1975-2004), and the famous Preface to the Contribution to the Critique of Political Economy, Marx finally chose to begin Capital not with production, but with the commodity relation as the fundamental unit of analysis of bourgeois society, the point where he began in 1844 .

The various institutions that populate the world should not be seen as necessarily determined by the capitalist mode of production. Regulation theory shows how in each country, in each epoch, capitalist accumulation is regulated by particular institutions, and the psychology of those living within them is determined not by a capitalist totality, but by these particular institutions ("objective spirit" in Hegel's terminology), which exist only through a certain constellation of cultural material and people oriented to their existence, subject to crisis and transformation, each according to their own dynamics.

Complementary to the great social institutions governing the life of individuals in modern society is what Bourdieu (1984) called "habitus" ("subjective spirit" in Hegel's terminology), the practical dispositions through which people understand and assert their place and membership of the myriad of "class fractions." Although generally regarded as an extreme "objectivist," Bourdieu has given us a rich source of conceptions of the practical activity and cultural resources through which people shape their own body and construct their consciousness.

The other important component of the problem of individual agency is cultural criticism (where Vygotsky began from). Those theorists who see postmodernism as an all-pervasive commodity aesthetics ("the cultural logic of late capitalism") in which no subversive position is possible, contribute to the mystification of agency. On the other hand, those theorists who see postmodern culture as an "arena of struggle," the location of "culture wars," offer an avenue for the critical appropriation of cultural theory. In each case, the relevant social forms can be critically appropriated in a conception of the subject that coordinates psyche, artifacts, and social relations.

To return to psychology, the immediate impact of the suggested approach is that it obliges a critical conception of the cultural and social formations that figure in the constitution of consciousness. For example, if an individual participates in some form of social practice, mediated by certain artifacts, the artifacts and the institution are not given objects, but entities instantiated by the psychology of the individuals concerned, within the constraints imposed by nature. We understand that the artifact is a material thing whose meaning is established only in and through the activity of individuals in social practice using the artifact, and we understand that the institution is constituted only by a discourse governing the collaborative (or competing) activity of individuals oriented to that discourse/institution. In every case it can be determined exactly how and to what extent an individual is capable of exercising genuine practical freedom in transforming institutions and discourses. If a social formation is accepted as a given, material entity (e.g., a state) then exercise of individual agency in relation to that entity is impossible. Once we accept that the power and ideology of the state exists only in and through individuals acting in line with that power and ideology, the state enters our analysis as open to transformation by the action of individuals. Likewise, once we accept that an artifact 
has significance only to the extent that individuals use the artifact in a given way, that artifact ceases to be an objectively given fact but becomes open to criticism.

This approach opens the way to a solution of the problem of individual agency. Among the outcomes of such an approach is the realization that an individual cannot, at least in history up to the present, be a subject, a sovereign power in their own right. Subjectivity can be exercised only in concert with others, in definite social relations. Such relations can be understood only through the concept of subject, as a self-conscious system of activity, in which agency, cogito, and self-consciousness relatively coincide, through the mediation of the individual psyche, artifacts and definite social relations.

\section{REFERENCES}

Billett, S. (2006). Activity as object-related: Resolving the dichotomy of individual and collective planes of activity. Mind, Culture, and Activity, 13, 53-69.

Bourdieu, P. (1984). Distinctions. Cambridge, MA: Harvard University Press.

Boyer, R. (1990). The regulation school. New York: Columbia University Press.

Fichte, J. (2000). Foundations of natural right. In F. Neuhouser (Ed.), Foundations of natural right according to the Principles of the Wissenschaftslehre (pp. 3-334). Cambridge, UK: Cambridge University Press.

Habermas, J. (1987). The philosophical discourse of modernity. Cambridge, MA: MIT Press.

Hegel, G. W. F. (1969). Hegel's science of logic (A. V. Miller, Trans.). New York: George Allen \& Unwin.

Hegel, G. W. F. (1979). System of ethical life (1802/3) and First Philosophy of Spirit (1803-4) (T. M. Knox, Trans.). New York: State University of New York Press.

Heller, A. (1988). General ethics. Cambridge, MA: Blackwell.

Holland, D., Lachicotte, W., Skinner, D., \& Cain, C. (2001). Identity and agency in cultural worlds. Cambridge, MA: Harvard University Press.

Kautsky, K. (1902). The aims and limitations of the materialist conception of history. The Social Democrat, 6, 340-348. (Original work published 1896)

Leontyev, A. N. (1977). Activity and personality. In Philosophy in the USSR: Problems of Dialectical Materialism (pp. 180-202). Moscow: Progress Publishers.

Leontyev, A. N. (1978). Activity, consciousness and personality. Retrieved October 23, 2006, http://lchc.ucsd.edu/ MCA/Paper/leontev/index.html

Marx, K., \& Engels, F. (1975-2004). Marx-Engels collected works (Vols. 1-50). London: Lawrence \& Wishart.

Peirce, C. S. (1931-1958). Collected papers. Cambridge, MA: Harvard University Press.

Putnam, R. D. (1993). Making democracy work. Princeton, NJ: Princeton University Press.

Putnam, R. D. (2000). Bowling alone. New York: Simon and Schuster.

Stetsenko, A. (2005). Relational interdependence between social and individual agency in work and working life. Mind, Culture, and Activity, 12, 70-88.

Vygotsky, L. S. (1987-1999). Collected works (Vols. 1-6) New York: Plenum. 